\title{
Severe respiratory distress in term infants born electively at high altitude
}

\author{
Ahmad F Bakr*1,3,4 and Mohammad M Abbas²
}

Address: ${ }^{1}$ Departments of Pediatrics, University of Alexandria, Alexandria, Egypt, ${ }^{2}$ Departments of Obstetrics, King Abdul-Aziz Specialist Hospital, Taif, Saudi Arabia, ${ }^{3}$ Consultant Neonatologist, Welcare Hospital, PO Box 31500 Dubai, United Arab Emirates and ${ }^{4}$ Obstetrics and Gynecology, Faculty of Medicine, University of Alexandria, Egypt

Email: Ahmad F Bakr* - afb1963@hotmail.com; Mohammad M Abbas - mmabbas@yahoo.com

* Corresponding author

Published: 16 February 2006

BMC Pregnancy and Childbirth 2006, 6:4 doi:10.1 186/147I-2393-6-4

This article is available from: http://www.biomedcentral.com/I47/-2393/6/4

(C) 2006 Bakr and Abbas; licensee BioMed Central Ltd.

This is an Open Access article distributed under the terms of the Creative Commons Attribution License (http://creativecommons.org/licenses/by/2.0), which permits unrestricted use, distribution, and reproduction in any medium, provided the original work is properly cited.
Received: 04 August 2005

Accepted: 16 February 2006

\begin{abstract}
Background: We studied the contribution of elective delivery to severe respiratory distress syndrome (RDS) in term babies born at high altitude.

Methods: We prospectively studied the charts of term babies born in Taif Maternity Hospital (1640 m above sea level) between I/I/2004 and 31//0/2004 who developed RDS and required mechanical ventilation.

Results: 8634 deliveries occurred from $37-<4$ I weeks; I 3 (0.15\%) had RDS requiring mechanical ventilation. Seven infants delivered at $37-<38$ weeks, (OR for RDS $=2695 \% \mathrm{Cl}-4.6$ to 5.8 ), five delivered at 38-<39 weeks, (OR for RDS $=1095 \% \mathrm{Cl}-4.9$ to 5.4 ) and one delivered at $>39$ weeks. Six of 13 infants were electively delivered without documented lung maturity.

Conclusion: Infants born at 37 and 38 weeks' gestation remain at significantly increased risk for severe RDS. Elective delivery is responsible for $50 \%$ of the potentially avoidable cases. Our data suggest that the altitude does not seem to influence the incidence of severe RDS in term infants born electively.
\end{abstract}

\section{Background}

Respiratory distress syndrome (RDS) is a common problem in neonatal practice, usually seen in premature babies. Iatrogenic RDS is defined as RDS resulting from elective delivery [1]. Worldwide, iatrogenic RDS persists as a cause of neonatal morbidity and mortality [2,3]. Nonadherence to the guidelines [4] designed to minimize the risk of electively delivering an immature infant can lead to iatrogenic RDS. This problem is further augmented in developing countries where good antenatal care is not always the rule. Not knowing the expected dates of delivery accurately by the patient and/or the treating physician is not uncommon. Further contributing to the problem is the variable definition of a term pregnancy. Fetal lung maturity cannot be assumed with certainty until 39 weeks' gestation [5]. The concept of maturity is even more different in some communities, including the educated, in developing countries.

Obstetric practice in Taif is peculiar. The incidence of high gravidity and parity is common and elective sections tend to be done earlier for fear of scar dehiscence. Also Taif lies at high altitude; $1640 \mathrm{~m}$ above sea level. High altitude implies a decrease in the atmospheric pressure and consequently oxygenation. It is known to cause intrauterine growth restriction (IUGR), which raises neonatal mortal- 
Table I: Maternal and Neonatal Characteristics of Index Cases (Mean \pm SD)

\begin{tabular}{|c|c|c|c|}
\hline & \multicolumn{3}{|c|}{ Gestational Age at Delivery } \\
\hline & $37-<38(n=7)$ & $38-<39(n=5)$ & $39-\leq 4 \mathrm{I}(\mathrm{n}=1)$ \\
\hline \multicolumn{4}{|l|}{ Maternal Data } \\
\hline • Age (years) & $30.8 \pm 4.2$ & $29.3 \pm 5.8$ & 30.7 \\
\hline \multicolumn{4}{|l|}{ - Parity } \\
\hline 0 & 1 & I & 0 \\
\hline 1 & 2 & I & 1 \\
\hline$\geq 2$ & 4 & 3 & 1 \\
\hline - Cesarean Delivery & 2 & 3 & 1 \\
\hline \multicolumn{4}{|l|}{ Newborn Data } \\
\hline - Birth weight (g) & $2770 \pm 425$ & $3070 \pm 350$ & 3140 \\
\hline - 5-min Apgar < 7 & 1 & 0 & 0 \\
\hline - Ventilator Days & $4.6 \pm 2$ & $3.7 \pm 2.1$ & 3 \\
\hline - Surfactant given & 5 & 3 & 0 \\
\hline - Hospital Stay (days) & $12.4 \pm 3.7$ & $11.7 \pm 3.8$ & 11 \\
\hline - Air Leak & 2 & I & 1 \\
\hline - Deaths & I & 1 & 0 \\
\hline
\end{tabular}

ity. However, existing studies are unclear as to whether IUGR-specific mortality at high altitude is similar to, less than, or greater than at low altitude $[6,7]$. Whether this is associated with a protective beneficial effect on lung maturity or not is not clear. Whether this should change or not the guidelines for elective delivery is also not clear and has to be studied.

We planned to determine the incidence of severe RDS requiring mechanical ventilation at term among those delivered electively at high altitude.

\section{Methods}

This study was carried-out in the maternity section of King Abul-Aziz Specialist Hospital in Taif (1640 m above sea level) between 1/1/2004 and 31/10/2004. The study was approved by KAASH ethical committee. Taif Maternity Hospital is a large urban institution with approximately 12,000 deliveries per year. All newborns delivered at 37 weeks' gestation or more and having severe RDS requiring mechanical ventilation were enrolled in the study. Exclusion criteria included any cause of respiratory distress apart from RDS (sepsis, pneumonia, meconium aspiration, asphyxia, pulmonary hemorrhage and congenital abnormalities).

The diagnosis of RDS was made by the NICU staff. Every patient record was reviewed by a neonatologist to confirm the diagnosis and to ensure the absence of exclusion criteria. RDS was diagnosed by the classic clinical and radiological signs of respiratory distress syndrome. Oxygen and ventilator requirements were recorded. The mothers' files were checked to confirm gestational age and to identify the reason for delivery. Deliveries were classified as spontaneous (mother presented in labor), indicated (obstetric or medical reasons), and elective (mother not in labor and no maternal or fetal condition warranting delivery). The differences in outcomes in relation to gestational age were analyzed. Comparisons with figures at sea level were done when applicable. Paired t-test was performed, p values < 0.05 were considered significant. Odds ratio and 95\% confidence intervals were calculated..5

\section{Results}

During the study period, 8634 infants were delivered between 37 and 41 weeks' gestation. Of these children, $1338(15.5 \%)$ delivered at $37-<38,2478(28.7 \%)$ at 38 - <39, and $4818(55.8 \%)$ at $39-<41$ weeks. Thirteen $(0.15 \%)$ of these infants experienced RDS requiring mechanical ventilation.

The maternal and neonatal demographic data were not significantly different at different gestational ages (Table 1 ). None of the mothers of the index cases received antenatal steroids.

Seven of the affected infants were delivered at 37-38 weeks (5.2/1000 births) (OR $=26,95 \% \mathrm{CI}-4.6$ to 5.8$)$. Five patients delivered at 38-39 weeks, (2/1000 births) $(\mathrm{OR}=1095 \% \mathrm{CI}-4.9$ to 5.4$)$. One infant was born between 39-41 weeks, (0.2 per 1000 births) [Comparison group]. None of these children developed chronic lung disease.

Out of the thirteen infants, six (46.15\%) were delivered electively. All of the six neonates were born at $<39$ weeks' gestation without an assessment of fetal lung maturity. (Table 2). Further complications including air leaks or pulmonary hypertension were reported in four out of the six $(66.7 \%)$. The frequency of RDS requiring mechanical 
Table 2: Data of Infants with iatrogenic RDS

\begin{tabular}{ccccc}
\hline Case & $\begin{array}{c}\text { Gestation Age }(\text { Wks }+ \\
\text { D)* }\end{array}$ & Birth Weight $(\mathrm{g})$ & Ventilator Days & Elective Delivery \\
\hline 1 & $38+1$ & 3450 & 4 & Planned repeat CS \\
2 & $37+3$ & 3050 & 2 & Breech, not in labor \\
3 & 38 & 3700 & 5 & Planned repeat CS \\
4 & $38+4$ & 3200 & 2 & Planned repeat CS \\
5 & 37 & 3300 & 1 & Planned repeat CS \\
6 & $38+2$ & 3750 & 11 & Planned repeat CS \\
\hline
\end{tabular}

* Calculated from first day of last menstrual period

ventilation following elective delivery was not different than that observed after indicated or spontaneous delivery, either overall or when stratified by gestational age.

\section{Discussion}

In our series, we found that infants born at 37 and 38 weeks' gestation experience a 26-fold and 10-fold increased risk of severe RDS, respectively, as compared with 39 to 41 weeks' newborns. Our observed rates of RDS stratified by weeks of gestation are comparable to those reported by Madar et al [8]. Two studies reported higher rates of term RDS. The methodology of the first one was similar to ours [2]. However the study of Bowers et al [9] did not require the use of positive pressure ventilation in diagnosing RDS. Their higher rates more likely reflected the inclusion of the more common mild cases of neonatal respiratory distress.

The primary objective of this study was to assess the contribution of elective delivery to severe neonatal RDS. In our study, this practice was responsible for $46 \%$ of severe RDS at 37 and 38 weeks' gestation. Bowers et al [9] reported in 1982 that over 33\% of newborn RDS was iatrogenic. Madar et al [8] concluded that babies who are not premature, using the internationally agreed definition, can show signs of potentially lethal pulmonary immaturity at birth, especially if subjected to pre-labour caesarean delivery. Those born at 37-38 wk are 120 times more likely to receive ventilatory support for surfactant deficiency than those born at 39-41 wk. Later on, the reports varied significantly [10]. Zanardo et al stated that infants born by elective caesarean delivery at term are at increased risk for developing respiratory disorders compared with those born by vaginal delivery. A significant reduction in neonatal RDS would be obtained if elective caesarean delivery were performed after $39+0$ gestational weeks of pregnancy [11].

Cesarean delivery, especially when performed before the onset of labor, incurs additional risk of neonatal respiratory complications [12-14]. This risk is attributable to pulmonary immaturity, and the lack of the beneficial effects of normal labor on the newborn. These effects include reduction in lung water, enhanced cathecholamine levels, secretion of surfactant stores into the alveolar space, and increased levels of pulmonary vasodilating substances [15-19]. In our series, all of the electively delivered patients whose infants experienced RDS underwent scheduled cesarean delivery before labor and without assessment of lung maturity. This findings is consistent with other studies noting that $60-100 \%$ of electively delivered infants with RDS were born by cesarean [20].

Neonatal morbidity in term infants with RDS requiring mechanical ventilation was severe. Nearly thirty per cent had pulmonary air leak, most of them were electively delivered. This coincides with the findings of other studies that reported air leaks in 34\%, pulmonary hypertension in $20 \%$ and requiring ECMO in 16\% of infants with RDS following elective delivery $[10,13]$.

Deaths occurred in $15 \%$ in our series, while it is none in most of the other reports. The two deaths in our series were among those electively delivered before 39 weeks. In fact, the high mortality rate among newborn babies undergoing mechanical ventilation is high in developing countries regardless the indication of ventilation. The RDS, which necessitated mechanical ventilation, is related to the morbidity of these newborns, while the high mortality rate is more directly related to the level of neonatal intensive care in developing countries. Testing for fetal lung maturity is not routinely practiced in developing countries.

Many studies looked at the effect of high altitudes on neonatal outcome.[21,22] However, none studied the incidence of iatrogenic RDS in such environment. It was wellshown that the incidence of IUGR is higher in pregnancies at high altitudes $[6,7]$. In our study, the average birth weights seemed lower than those normally recorded at comparable gestational ages. However, we did not have lower incidence of term RDS in our series compared to other studies done at sea level $[2,3,8,11]$. One of the limitations of our study was that we did not compare our results with a similar centre at sea level. Another limitation is that the number of term infants who had severe 
RDS is small to draw solid conclusions with regards to the relation with high altitude. Further long term studies involving larger numbers of cases and those done simultaneously at different altitudes can draw better conclusions.

Iatrogenic RDS may result from misinterpreting clinical or sonographic data, nonadherence to clinical protocols, or failing to perform amniocentesis to assess fetal lung maturity. Strategies to minimize the chance of electively delivering an immature fetus include awaiting onset of spontaneous labor (when applicable) before performing cesarean delivery, appropriate interpretation of clinical dating and ultrasound parameters, or obtaining amniotic fluid lung maturity studies [1-4]. In our study, none of the infants was tested for lung maturity. Adherence to the recommended guidelines may have avoided most of the morbidities.

\section{Conclusion and recommendations}

Infants born at 37 and 38 weeks' gestation remain at significantly increased risk for severe RDS. Fifty per cent of severe RDS cases at these gestational ages followed elective delivery without prior assessment of fetal lung maturity, and were potentially avoidable. Adherence to clinical protocols should minimize the frequency with which severe RDS occurs in term newborn. In comparison with previous studies made at sea level, our data suggest that the altitude does not seem to influence the incidence of severe RDS in term infants born electively. Further wellplanned multicenter studies are needed.

\section{Competing interests}

The author(s) declare that they have no competing interests.

\section{Authors' contributions}

$\mathrm{AB}$ carried out the study design, data collection, analysis and writing of the manuscript. MA shared participated in the design of the study and shared in the data collection. All authors read and approved the final manuscript.

\section{References}

I. Parilla BV, Dooley SL, Jansen RD: latrogenic respiratory distress syndrome following elective repeat cesarean delivery. Obstet Gynecol 1993, 83:392-5.

2. Wax JR, Herson V, Carignan E, Mather J, Ingardia CJ: Contribution of elective delivery to severe respiratory distress at term. Am J Perinatol 2002, I 9(2):8I-6.

3. Le Guennec JC, Bard H, Teasdale F, Doray B: Elective delivery and the neonatal respiratory distress syndrome. Can Med Assoc J 1980, I 22(3):307-9.

4. American College of Obstetricians and Gynecologists: Assessment of fetal lung maturity. ACOG Education Bulletin no. 230. Washington, DC: American College of Obstetricians and Gynecologists; 1996.

5. European Congress of Perinatal Medicine: Working party to discuss nomenclature based on gestational age and birthweight. Arch Dis Child 1970, 45:730-I.
6. Moore LG: Fetal growth restriction and maternal oxygen transport during high altitude pregnancy. High Alt Med Biol 2003, 4(2): $14 \mid-56$.

7. Kametas NA, Krampl E, McAuliffe F, Rampling MW, Nicolaides KH: Pregnancy at high altitude: a hyperviscosity state. Acta Obstet Gynecol Scand 2004, 83(7):627-33.

8. Madar J, Richmond S, Hey E: Surfactant-deficient respiratory distress after elective delivery at "term". Acta Paediatr 1999, 88: $1244-8$.

9. Bowers SK, MacDonald HM, Shapiro ED: Prevention of iatrogenic neonatal respiratory distress syndrome: elective repeat cesarean section and spontaneous labor. Am J Obstet Gynecol 1982, 143:186-9.

10. Morrison JJ, Rennie JM, Milton PJ: Neonatal respiratory morbidity and mode of delivery at term: influence of timing of elective cesarean section. BrJ Obstet Gynaecol 1995, 102:101-6.

II. Zanardo V, Simbi AK, Franzoi M, Solda G, Salvadori A, Trevisanuto D: Neonatal respiratory morbidity risk and mode of delivery at term: influence of timing of elective caesarean delivery. Acta Paediatr 2004, 93(5):643-7.

12. Lewis DF, Fontenot MT, Robichaux AG, Stedman CM, Jaekle RK, Evans AT: Respiratory morbidity in well-dated twins approaching term. What are the risks of elective delivery? J Reprod Med 2002, 47(10):84I-4.

13. Curet LB, Zachman RD, Rao AV, Poole WK, Morrison J, Burkett G: Effect of mode of delivery on incidence of respiratory distress syndrome. Int J Gynecol Obstet 1988, 27:165- I 70.

14. Nielsen TF, Hokegard KH: The incidence of acute neonatal respiratory disorders in relation to mode of delivery. Acta Obstet Gynecol Scand 1984, 63:109-14.

15. Brown MJ, Oliver RE, Ramsden CA: Effects of adrenaline and of spontaneous labour on the secretion and absorption of lung fluid in the foetal lamb. J Physiol 1983, 344: I37-52.

16. Irestedt L, Lagercrantz H, Hjemdahl P, Hagnevik K, Belfrage P: Fetal and maternal plasma cathecholamine levels at elective cesarean section under general and epidural anesthesia versus vaginal delivery. Am J Obstet Gynecol 1982, I42:1004-I0.

17. Marino PA, Roney SA: The effect of labor on surfactant secretion in newborn lung slices. Biochem Biophys Acta 1981, 664:389-90.

18. Bibby JG, Brunt JD, Hodgson H: Prostaglandins in umbilical plasma at elective cesarean section. Br J Obstet Gynaecol 1979, 86:282-284.

19. Hales KA, Morgan MA, Thurnau GR: Influence of labor and route of delivery on the frequency of respiratory morbidity in term neonates. Int J Gynaecol Obstet 1993, 43(I):35-40.

20. Schreiner RL, Stevens DC, Smith WL, Lemons JA, Golichowski AM, Padilla LM: Respiratory distress following elective repeat cesarean section. Am J Obstet Gynecol 1982, 143:689-92.

21. Moore LG, Shriver M, Bemis L: Maternal adaptation to high-altitude pregnancy: an experiment of nature - a review. Placenta 2004, 25(Suppl A):S60-7I.

22. Flaksman RJ, Vollman JH, Benfield DG: Physiological basis for recommendations regarding exercise during pregnancy at high altitude. High Alt Med Biol 2004, 5(3):321-34.

\section{Pre-publication history}

The pre-publication history for this paper can be accessed here:

http://www.biomedcentral.com/1471-2393/6/4/prepub 